\title{
Obesity Fact Sheet in Korea, 2018: Data Focusing on Waist Circumference and Obesity-Related Comorbidities
}

Ga Eun Nam', Yang-Hyun Kim', Kyungdo Han², Jin-Hyung Jung², Yong Gyu Park², Kwan-Woo Lee², Eun-Jung Rhee4, Jang Won Son ${ }^{5}$, Seong-Su Lee, Hyuk-Sang Kwon ${ }^{6}$, Won-Young Lee, ${ }^{4, *}$, Soon Jib Yoo ${ }^{5, *}$, on behalf of the Taskforce Team of the Obesity Fact Sheet of the Korean Society for the Study of Obesity

${ }^{1}$ Department of Family Medicine, Korea University College of Medicine, Seoul; ${ }^{2}$ Department of Biostatistics, College of Medicine, The Catholic University of Korea, Seoul; ${ }^{3}$ Department of Endocrinology and Metabolism, Ajou University School of Medicine, Suwon; ${ }^{4}$ Division of Endocrinology and Metabolism, Department of Internal Medicine, Kangbuk Samsung Hospital, Sungkyunkwan University School of Medicine, Seoul; ${ }^{5}$ Division of Endocrinology and Metabolism, Department of Internal Medicine, Bucheon St. Mary's Hospital, College of Medicine, The Catholic University of Korea, Bucheon; ${ }^{6}$ Division of Endocrinology and Metabolism, Department of Internal Medicine, Yeouido St. Mary's Hospital, College of Medicine, The Catholic University of Korea, Seoul, Korea

Background: The global prevalence of obesity has increased steadily in recent years. Waist circumference (WC) reflects body composition better than body mass index. The Korean Society for the Study of Obesity released the 2018 Obesity Fact Sheet to address the incidence of obesity-related comorbidities according to WC levels. Methods: Data from the Korean National Health Insurance Service health examination database from 2009 to 2016 were analyzed. Abdominal obesity was defined as a WC $\geq 90 \mathrm{~cm}$ in men and $\geq 85 \mathrm{~cm}$ in women. Incidence rates of comorbidities and all-cause mortality rates were calculated after standardizing by age and sex based on the 2010 census.

Results: From 2009 to 2015, the incidence rates of type 2 diabetes mellitus, hypertension, myocardial infarction, and ischemic stroke increased both in men and women. Individuals with the lowest WC levels had the highest all-cause mortality rates followed by those with the highest WC levels in men, women, and the total population. The incidence rates of total cancer increased as WC levels escalated between 2009 and 2016. In men, the incidence rates of colorectal, prostate, and liver cancers increased as WC levels increased. The incidence rates of thyroid, colorectal, and stomach cancers increased as WC levels rose in women. In addition, medical expenses continuously increased as WC increased in both men and women.

Conclusion: Based on the 2018 Obesity Fact Sheet, strategies for reducing the abdominal obesity and related comorbidities and medical expenses are a public health priority.

Key words: Abdominal obesity, Obesity, Waist circumference, Comorbidity, Mortality, Fact sheet, National Health Insurance Service
Received December 3, 2019

Reviewed December 12, 2019

Accepted December 17, 2019

${ }^{*}$ Corresponding author

Won-Young Lee

(i) https://orcid.org/0000-0002-1082-7592

Division of Endocrinology and Metabolism, Department of Internal Medicine, Kangbuk Samsung Hospital, Sungkyunkwan University School of Medicine, 29 Saemunan-ro, Jongno-gu, Seoul 03181, Korea

Tel: +82-2-2001-2579

Fax: +82-2-2001-1588

E-mail:drlwy@hanmail.net

${ }^{*}$ Co-Corresponding author Soon Jib Yoo

https://orcid.org/0000-0002-9932-4130

Division of Endocrinology and Metabolism, Department of Internal Medicine, Bucheon St. Mary's Hospital, College of Medicine, The Catholic University of Korea, 327 Sosa-ro, Wonmi-gu, Bucheon 14647, Korea Tel: +82-32-340-7011

Fax: +82-32-340-2669

E-mail: sjyoo@catholic.ac.kr

The first two authors contributed equally to this study. 


\section{INTRODUCTION}

With its increased prevalence in recent decades, obesity is considered to be a global pandemic. In 2016, $\geq 39 \%$ of adults were overweight and $\geq 13 \%$ were obese worldwide. ${ }^{1,2}$ In Korea, the prevalence of obesity and abdominal obesity also increased steadily from 2009 to 2015. In 2015, the prevalence of obesity and abdominal obesity was $32.4 \%$ and $20.8 \%$, respectively. ${ }^{3}$ The increasing prevalence of obesity has led to a large health and economic burden worldwide because excess weight gain causes mortality and various chronic diseases such as type 2 diabetes mellitus, cardiovascular diseases (CVDs), and cancers. ${ }^{4}$ Although body mass index (BMI) is recognized as a clinical and epidemiologic tool for assessing obesity, BMI does not reflect body composition accurately; the same BMI range may be associated with substantial variations in total and visceral adiposity. ${ }^{5}$ Moreover, several studies suggest that BMI may not be a satisfactory predictor of mortality risk. . $^{6,7}$ Obesity-related comorbidities are more closely related to abdominal adiposity than with total body fat quantity. ${ }^{8}$ Therefore, waist circumference (WC) and abdominal obesity, in addition to BMI and general obesity, should be taken into account in the future for assessing risk of obesity-related health outcomes.

The Korean Society for the Study of Obesity (KSSO) has been dedicated to investigating the prevalence of obesity and associated comorbidities and, ultimately, to improve obesity-related health outcomes in Korea. For this purpose, the KSSO signed a memorandum of understanding (MOU) with the Korean National Health Insurance Corporation (NHIC) in 2015. These two organizations have published Obesity Fact Sheets since 2015 under this MOU. These fact sheets evaluate obesity status and impacts and provide health statistics for establishment of national health policy regarding obesity. The 2018 Obesity Fact Sheet focused on WC and the associated health outcomes such as type 2 diabetes mellitus, hypertension, myocardial infarction, ischemic stroke, cancers, and mortality rate. In addition, medical cost associated with BMIand WC-defined obesity was analyzed. Herein we reported the 2018 Obesity Fact Sheet's rationale and methods and discussed the obesity and abdominal obesity-related health outcomes.

\section{METHODS}

\section{Database and population}

This study was based on the national health examination database provided by the Korean National Health Insurance Service (NHIS). The NHIS is a nonprofit and single-payer system managed by the Korean NHIC. The NHIS supplies universal medical coverage for all Korean residents and reimburses healthcare providers based on a fee-for-service system. As the Korean NHIC provides health examinations at least every 2 years for all insured people, the NHIS retains health information of nearly all Koreans, including data on demographics, disease diagnosis according to the International Classification of Disease, 10th revision (ICD-10) codes, medical treatment, and health examinations. Detailed information of the Korean NHIS database has been described elsewhere. ${ }^{9,10}$ From this database, individuals aged $\geq 20$ years who had undergone a health examination provided by the Korean NHIS between January 1, 2009 and December 31, 2009 were included for the analyses. We excluded individuals who had been diagnosed with study outcomes (type 2 diabetes mellitus, hypertension, myocardial infarction, ischemic stroke, and cancers) before January 1 , 2009. These cases were followed up until December 31, 2015 for the obesity-related comorbidities and all-cause death. As for cancer incidence, participants were tracked until December 31, 2016. The protocol of this study was approved by the Institutional Review Board of the Korea University Anam Hospital (IRB No. 2017AN0188) and the Korea National Institute for Bioethics Policy (No. NHIS2018-4-058).

\section{Definitions of obesity and abdominal obesity}

Participants' height, body weight, and WC were measured. BMI was calculated by dividing body weight in kilograms by the square of the height in meters. Obesity was defined as a BMI $\geq 25 \mathrm{~kg} / \mathrm{m}^{2}$ in accordance with the Asia-Pacific criteria of the World Health Organization guidelines. ${ }^{11}$ Abdominal obesity was defined as a WC $\geq 90 \mathrm{~cm}$ in men and $\geq 85 \mathrm{~cm}$ in women in accordance with the definition of the KSSO. ${ }^{12,13}$ Six levels of WC generated with $5-\mathrm{cm}$ increments were categorized: level $1,<80 \mathrm{~cm}$ in men and $<75 \mathrm{~cm}$ in women; level $2,80-85 \mathrm{~cm}$ in men and $75-80 \mathrm{~cm}$ in women; level $3,85-90 \mathrm{~cm}$ in men and $80-85 \mathrm{~cm}$ in women; level $4,90-95 \mathrm{~cm}$ in 
men and 85-90 cm in women; level 5, 95-100 cm in men and 90$95 \mathrm{~cm}$ in women; and level $6, \geq 100 \mathrm{~cm}$ in men and $\geq 95 \mathrm{~cm}$ in women.

\section{Definition of comorbidities}

Type 2 diabetes mellitus was defined as a fasting plasma glucose level of $\geq 126 \mathrm{mg} / \mathrm{dL}$ or at least one claim per year for prescription of antidiabetic medication under ICD-10 codes E11-E14. ${ }^{14}$ Hypertension was defined as blood pressure $\geq 140 / 90 \mathrm{mmHg}$ or at least one claim per year for prescription of antihypertensive medication under ICD-10 codes I10-I15. Myocardial infarction was defined as an event-related hospitalization under ICD-10 code I21 or I22.

Ischemic stroke was defined as an event-related hospitalization un- der ICD-10 code I63 or I64 and claims for brain magnetic resonance imaging or computed tomography. Cancer was defined as ICD-10 codes for cancers and registration code (V193) for cancers. Total cancer referred to all cancers with the ICD-10 "C" code.

\section{Annual medical expenses}

We used the NHIS-National Sample Cohort between 2010 and 2015 to assess the annual medical expenses per patient. The annual medical expenses were estimated using a two-part model after adjusting for age and comorbidities (type 2 diabetes mellitus, hypertension, myocardial infarction, dyslipidemia, and ischemic stroke). In this analysis, we excluded patients with cancer, human immunodeficiency virus, hemophilia, third degree burns, transplanted or-

Table 1. Incidence of obesity-related comorbidities according to waist circumference levels

\begin{tabular}{|c|c|c|c|c|c|c|c|}
\hline \multirow{2}{*}{ Variable } & & \multicolumn{6}{|c|}{ Waist circumference } \\
\hline & & Level 1 & Level 2 & Level 3 & Level 4 & Level 5 & Level 6 \\
\hline \multicolumn{8}{|c|}{ Type 2 diabetes mellitus } \\
\hline \multirow[t]{2}{*}{ Total } & $\mathrm{n}$ & $3,556,515$ & 2,199,185 & $1,763,306$ & 989,823 & 421,828 & 215,304 \\
\hline & $\mathbb{R}$ & 2.8 & 4.5 & 6.7 & 9.4 & 12.9 & 19.5 \\
\hline \multirow[t]{2}{*}{ Men } & $\mathrm{n}$ & $1,546,735$ & $1,352,745$ & $1,093,902$ & 619,093 & 243,616 & 113,725 \\
\hline & $\mathbb{R}$ & 3.0 & 4.7 & 6.8 & 9.6 & 13.4 & 20.7 \\
\hline \multirow[t]{2}{*}{ Women } & $\mathrm{n}$ & $2,009,780$ & 846,440 & 669,404 & 370,730 & 178,212 & 101,579 \\
\hline & $\mathbb{R}$ & 2.6 & 4.4 & 6.6 & 9.5 & 12.4 & 18.4 \\
\hline \multicolumn{8}{|c|}{ Hypertension } \\
\hline \multirow[t]{2}{*}{ Total } & $\mathrm{n}$ & $3,162,873$ & $1,746,361$ & $1,262,011$ & 635,075 & 241,968 & 109,754 \\
\hline & $\mathbb{R}$ & 14.7 & 19.5 & 23.7 & 28.2 & 33.7 & 41.3 \\
\hline \multirow[t]{2}{*}{ Men } & $\mathrm{n}$ & $1,356,677$ & $1,094,106$ & 812,914 & 417,020 & 150,143 & 62,477 \\
\hline & $\mathbb{R}$ & 16.4 & 21.9 & 26.3 & 31.6 & 37.2 & 47.0 \\
\hline \multirow[t]{2}{*}{ Women } & $\mathrm{n}$ & 1,806,196 & 652,255 & 449,097 & 218,055 & 91,825 & 47,277 \\
\hline & $\mathbb{R}$ & 12.5 & 16.9 & 20.6 & 24.5 & 29.5 & 35.7 \\
\hline \multicolumn{8}{|c|}{ Myocardial infarction } \\
\hline \multirow[t]{2}{*}{ Total } & $\mathrm{n}$ & $3,580,527$ & 2,265,335 & $1,849,522$ & $1,062,506$ & 463,652 & 248,049 \\
\hline & $\mathbb{R}$ & 1.1 & 1.1 & 1.2 & 1.4 & 1.5 & 1.6 \\
\hline \multirow[t]{2}{*}{ Men } & $n$ & $1,578,384$ & $1,413,392$ & $1,165,763$ & 675,596 & 272,653 & 132,703 \\
\hline & $\mathbb{R}$ & 1.2 & 1.3 & 1.4 & 1.5 & 1.7 & 1.8 \\
\hline \multirow[t]{2}{*}{ Women } & $n$ & $2,002,143$ & 851,943 & 683,759 & 386,910 & 190,999 & 115,346 \\
\hline & $\mathbb{R}$ & 1.0 & 1.0 & 1.1 & 1.2 & 1.3 & 1.4 \\
\hline \multicolumn{8}{|c|}{ Ischemic stroke } \\
\hline \multirow[t]{2}{*}{ Total } & $\mathrm{n}$ & $3,580,527$ & $2,265,335$ & $1,849,522$ & $1,062,506$ & 463,652 & 248,049 \\
\hline & $\mathbb{R}$ & 1.7 & 1.8 & 1.9 & 2.0 & 2.2 & 2.4 \\
\hline \multirow[t]{2}{*}{ Men } & $\mathrm{n}$ & $1,578,384$ & $1,413,392$ & $1,165,763$ & 675,596 & 272,653 & 132,703 \\
\hline & $\mathbb{R}$ & 2.3 & 2.5 & 2.5 & 2.7 & 2.9 & 3.0 \\
\hline \multirow[t]{2}{*}{ Women } & $\mathrm{n}$ & $2,002,143$ & 851,943 & 683,759 & 386,910 & 190,999 & 115,346 \\
\hline & $\mathbb{R}$ & 1.1 & 1.2 & 1.4 & 1.5 & 1.6 & 1.9 \\
\hline
\end{tabular}

Incidence rates (IRs) per 1,000 person-years are presented standardized for age and sex based on the 2010 census of the Korean population. Waist circumference was categorized by 5-cm increments (level 1-6). Level 1, $<80 \mathrm{~cm}$ in men and $<75 \mathrm{~cm}$ in women; Level 2, 80-85 cm in men and 75-80 cm in women; Level 3, 85-90 cm in men and 80-85 cm in women; Level 4, 90-95 cm in men and 85-90 cm in women; Level 5, 95-100 cm in men and 90-95 cm in women; Level 6, $\geq 100 \mathrm{~cm}$ in men and $\geq 95 \mathrm{~cm}$ in women. 
gans, and pregnancy. The medical expenses included prescriptions reimbursed by the NHIS and those expenses associated with outpatient and inpatient services. All costs were converted to the 2015 Korean Republic Won (KRW).

\section{Statistical analysis}

The incidence rates of comorbidities and all-cause mortality per 1,000 person-years (PY) are presented standardized for age and sex using the 2010 census of the Korean population. The incidence rate of cancer per 100,000 PY is presented standardized for age and sex using the 2010 census of the Korean population. All statistical analyses were conducted using SAS version 9.4 (SAS Institute Inc., Cary, NC, USA).

\section{RESULTS}

\section{WC and incidence of chronic diseases}

Table 1 shows the incidence of chronic diseases according to WC levels between 2009 and 2015. As WC levels escalated, the incidence rates of type 2 diabetes mellitus, hypertension, myocardial infarction, and ischemic stroke increased both in men and women. Type 2 diabetes mellitus, hypertension, myocardial infarction, and ischemic stroke occurred in 19.5, 41.3, 1.6, and 2.4 per 1,000 PY, respectively, in individuals at WC level 6.

\section{WC and all-cause mortality}

Fig. 1 presents all-cause mortality rates according to WC levels between 2009 and 2015. Individuals at the lowest WC level (level 1) had the highest all-cause mortality rates followed by those at the highest WC level (level 6) in men, women, and the total population. The all-cause mortality rates per 1,000 PY were 5.4 and 4.9 for individuals at level 1 and level 6 of WC, respectively. The rate of all-cause mortality increased from level 4, to level 5, to level 6 of WC in the total population, in men, and in women.

\section{WC and incidence of cancers}

The incidence rates of total cancer increased as WC levels escalated between 2009 and 2016 (Fig. 2). In the level 6 WC of total, men, and women populations, total cancer occurred in 742.6, 781.1, and 705.8 individuals per 100,000 PY, respectively. Table 2 presents the incidence rates of five major types of cancer according to WC levels in men and women. In men, the incidence rates of colorectal, prostate, and liver cancers increased as WC levels increased. The incidence rates of thyroid, colorectal, and stomach

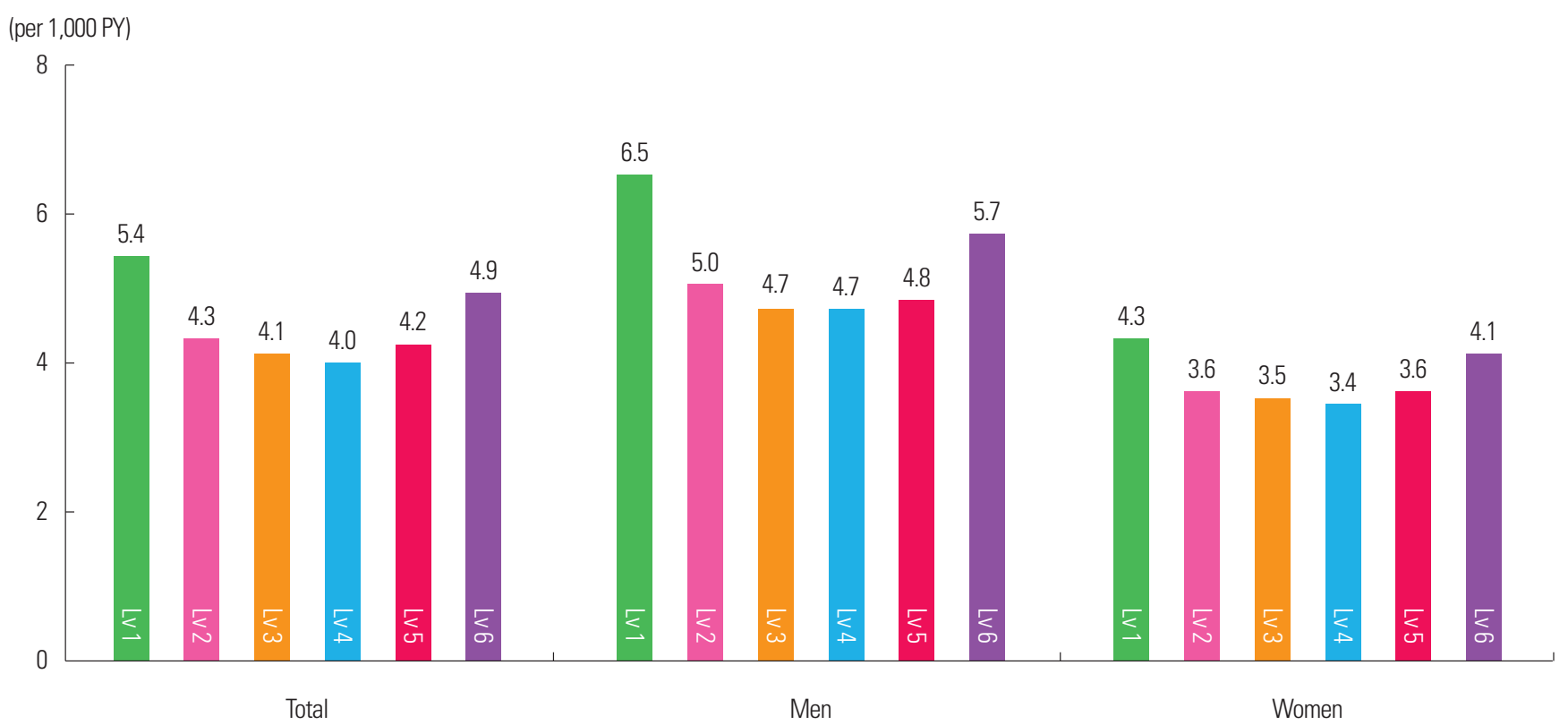

Figure 1. All-cause mortality according to waist circumference levels. Incidence rates per 1,000 person-years (PY) are presented standardized for age and sex based on the 2010 census of the Korean population. Waist circumference was categorized by 5-cm increments (level [Lv] 1-6). Lv 1, $<80 \mathrm{~cm}$ in men and <75 cm in women; Lv 2, $80-85$ $\mathrm{cm}$ in men and 75-80 cm in women; Lv 3, 85-90 cm in men and 80-85 cm in women; Lv 4, 90-95 cm in men and 85-90 cm in women; Lv 5, 95-100 cm in men and 90-95 $\mathrm{cm}$ in women; $\mathrm{Lv} 6, \geq 100 \mathrm{~cm}$ in men and $\geq 95 \mathrm{~cm}$ in women. 


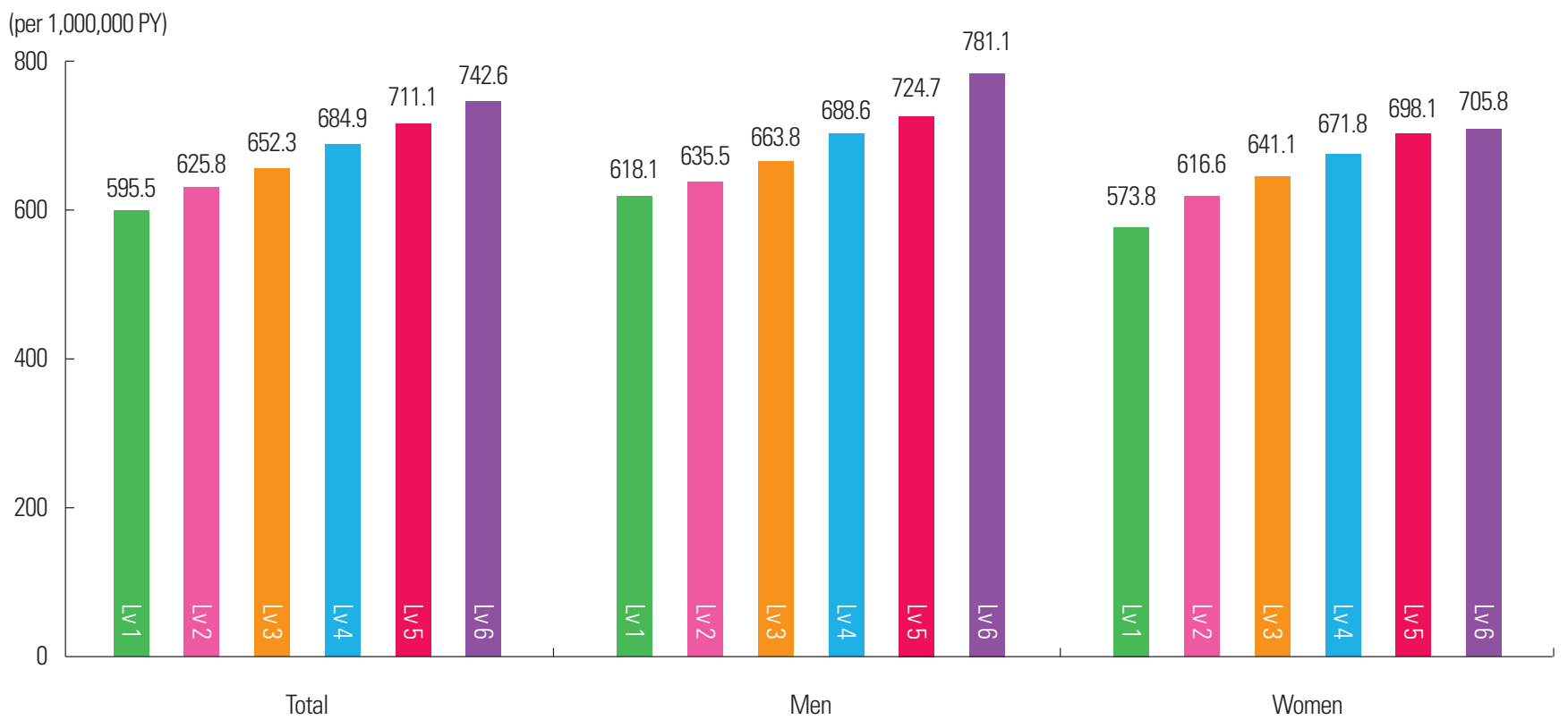

Figure 2. Incidence of total cancer according to waist circumference levels. Incidence rates per 100,000 person-years (PY) are presented standardized for age and sex based on the 2010 census of the Korean population. Waist circumference was categorized by 5-cm increments (level [Lv] 1-6). Lv 1, <80 cm in men and $<75 \mathrm{~cm}$ in women; Lv 2, 80-85 cm in men and 75-80 cm in women; Lv 3, 85-90 cm in men and 80-85 cm in women; Lv 4, 90-95 cm in men and 85-90 cm in women; Lv 5, 95-100 cm in men and $90-95 \mathrm{~cm}$ in women; $\mathrm{Lv} 6, \geq 100 \mathrm{~cm}$ in men and $\geq 95 \mathrm{~cm}$ in women.

Table 2. Incidence of five major types of cancer according to waist circumference levels in men and women

\begin{tabular}{lcccccc}
\hline \multirow{2}{*}{ Variable } & \multicolumn{6}{c}{ Waist circumference } \\
\cline { 2 - 7 } & Level 1 & Level 2 & Level 3 & Level 4 & Level 5 & Level 6 \\
\hline Men & $1,630,214$ & $1,480,066$ & $1,237,045$ & 726,438 & 296,676 & 145,326 \\
Number & 137 & 135 & 136 & 139 & 140 & 141 \\
Stomach cancer & 117 & 127 & 138 & 148 & 153 & 164 \\
Colorectal cancer & 117 & 98 & 97 & 95 & 93 & 100 \\
Lung cancer & 113 & 85 & 93 & 94 & 99 & 104 \\
Prostate cancer & 77 & 79 & 79 & 87 & 93 & 118 \\
Liver cancer & 77 & & & & & \\
Women & & & & & & \\
Number & $2,040,724$ & 896,923 & 742,461 & 432,342 & 219,263 & 135,039 \\
Thyroid cancer & 163 & 190 & 200 & 211 & 219 & 207 \\
Breast cancer & 104 & 108 & 109 & 109 & 111 & 108 \\
Colorectal cancer & 90 & 95 & 99 & 105 & 109 & 116 \\
Stomach cancer & 62 & 62 & 66 & 68 & 69 & 68 \\
Lung cancer & 43 & 43 & 42 & 43 & 43 & 44 \\
\hline
\end{tabular}

Incidence rates per 100,000 person-years are presented standardized for age and sex based on the 2010 census of the Korean population. Waist circumference was categorized by 5 -cm increments (level 1-6). Level 1, $<80 \mathrm{~cm}$ in men and $<75 \mathrm{~cm}$ in women; Level 2, 80-85 cm in men and 75-80 cm in women; Level 3, 85-90 cm in men and 80$85 \mathrm{~cm}$ in women; Level 4, 90-95 cm in men and 85-90 cm in women; Level 5, 95-100 $\mathrm{cm}$ in men and $90-95 \mathrm{~cm}$ in women; Level 6, $\geq 100 \mathrm{~cm}$ in men and $\geq 95 \mathrm{~cm}$ in women.

cancers increased as WC levels rose in women. Fig. 3 shows the incidence rate ratio for cancers in individuals with abdominal obesity compared to those without abdominal obesity. Men with abdomi- nal obesity showed greater incidence of lymphoma as well as renal, thyroid, bladder, colorectal, testicular, liver, biliary, prostate, and skin cancers than men without abdominal obesity. In women, individuals with abdominal obesity had increased incidence of uterine, renal, liver, biliary, bladder, nervous system, pancreatic, and colorectal cancers, leukemia, and lymphoma than those without abdominal obesity. Particularly, men with abdominal obesity showed 1.53 and 1.46 times greater incidence of renal and thyroid cancers, respectively, than those without abdominal obesity; women with abdominal obesity showed 1.56 and 1.33 times greater incidence of uterine corpus and renal cancers, respectively, than those without abdominal obesity.

\section{Obesity parameters and medical expenses}

Fig. 4 shows the annual medical expenses per patient by BMI and WC in age and sex groups. The medical expenses increased as the BMI increased to $35 \mathrm{~kg} / \mathrm{m}^{2}$ in the total population and men and to $30 \mathrm{~kg} / \mathrm{m}^{2}$ in women. Above those points, the medical expenses tended to decrease slightly with severe obesity. However, the medical expenses continuously increased as WC increased in both men and women. In all age groups older than 35 years, the annual medical expenses continuously increased as BMI and WC in- 
A

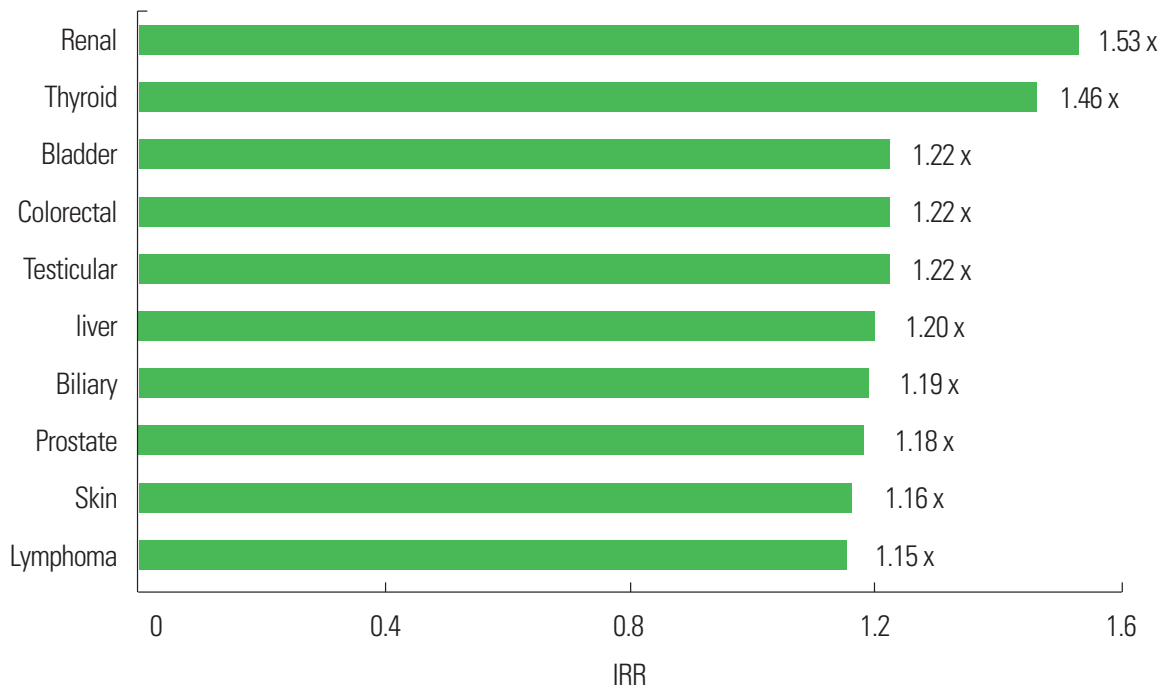

B

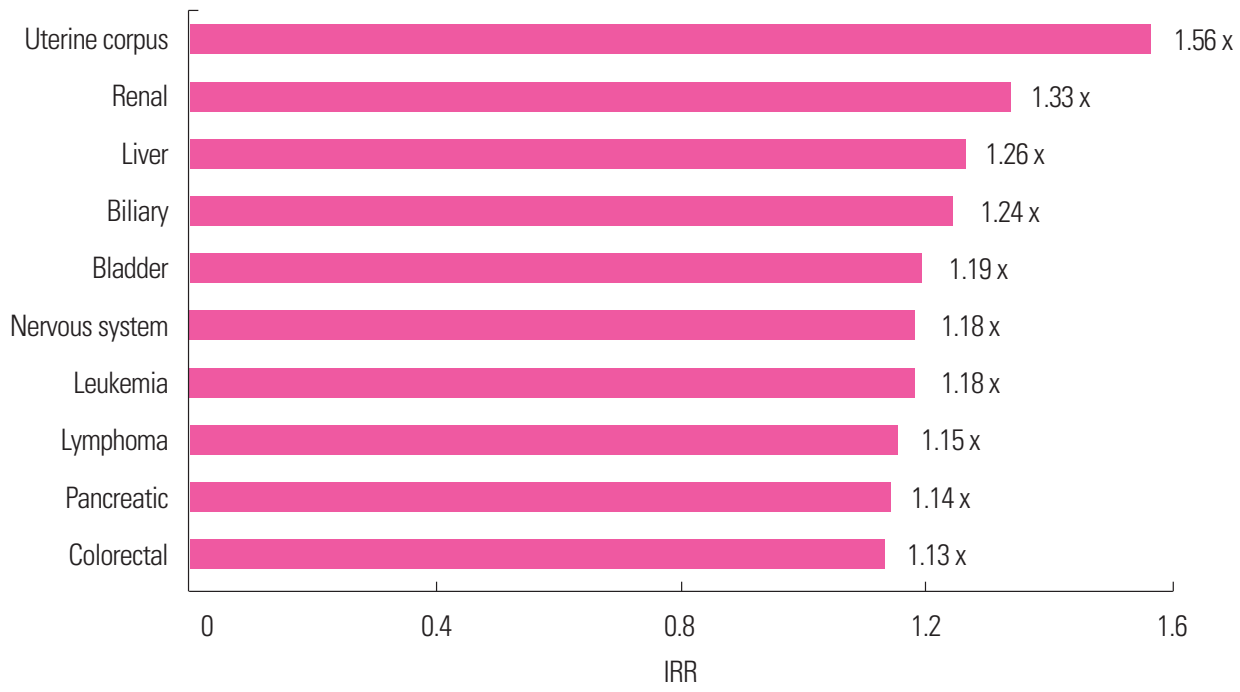

Figure 3. Incidence rate ratio (IRR) for cancers in men (A) and women (B) with abdominal obesity. Incidence rates per 100,000 person-years are presented standardized for age and sex based on the 2010 census of the Korean population. Abdominal obesity was defined as a waist circumference $\geq 90 \mathrm{~cm}$ in men and $\geq 85 \mathrm{~cm}$ in women.

creased. Additionally, in all BMI and WC groups, the rises in annual medical expenses were considerably greater for elderly individuals than for young individuals.

\section{DISCUSSION}

In this study, we found that the incidence of obesity-related comorbidities including type 2 diabetes mellitus, hypertension, myocardial infarction, and ischemic stroke has increased with increasing WC levels from 2009 to 2015 . From 2009 to 2016, incidence of total cancer, colorectal, prostate, and liver cancers in men and thyroid, colorectal, and stomach cancers in women increased with increasing WC levels. The mortality rate from all causes was the highest in individuals with the lowest WC level but followed by the highest level of WC. In addition, the annual medical expenses constantly increased with WC levels in individuals aged $\geq 35$ years. The results from the 2018 Obesity Fact Sheet suggest that greater levels of WC are associated with higher incidence of chronic diseases and all-cause mortality rates, and management for achieving appropriate $\mathrm{WC}$ is essential for reducing the incidence of chronic diseases and mortality rate.

Both hypertension and type 2 diabetes mellitus are associated 
A

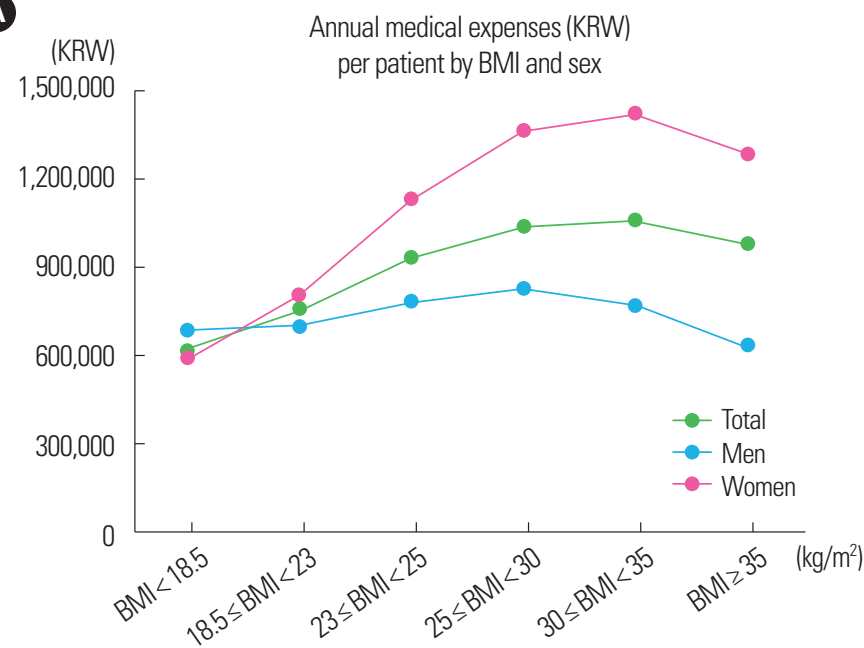

B

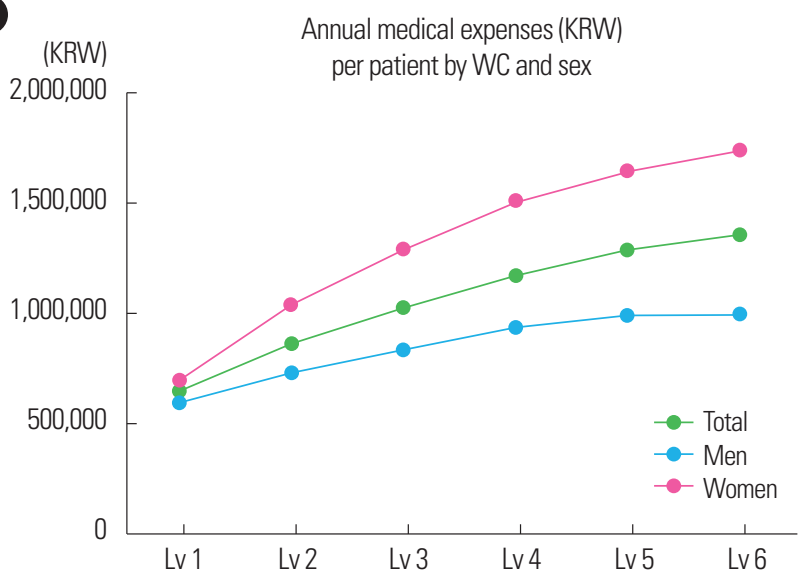

C

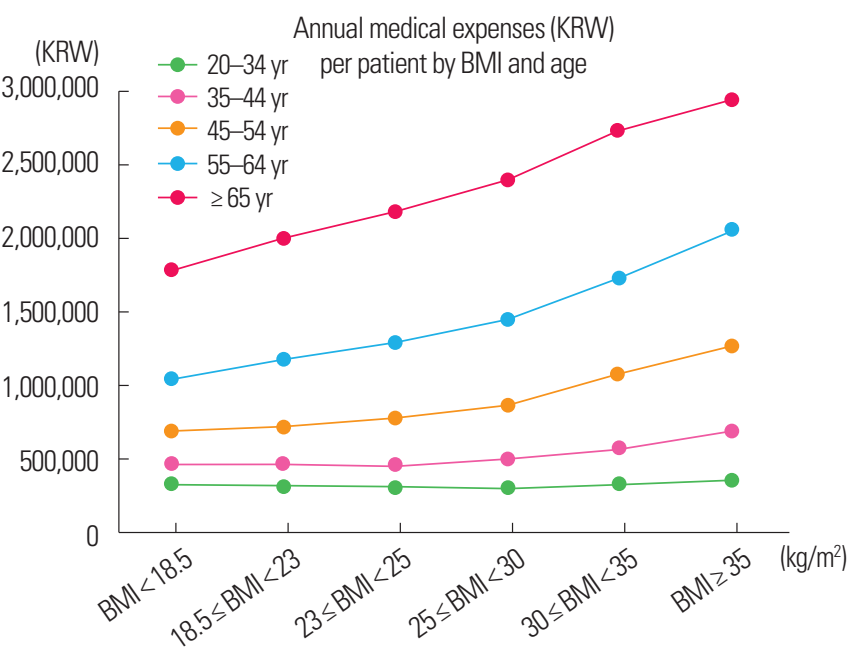

D

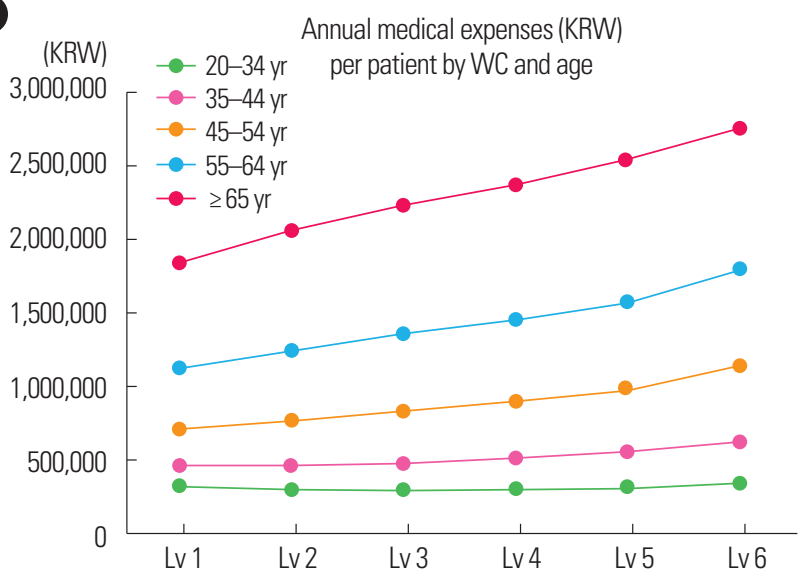

Figure 4. Annual medical expenses per patient by body mass index (BMI) and waist circumference (WC) according to sex (A, B) and age (C, D) groups. All expenses were converted to the 2015 Korean Republic Won (KRW). WC was categorized by 5-cm increments (level [Lv] 1-6). Lv 1, <80 cm in men and <75 cm in women; Lv 2, 80-85 cm in men and 75-80 cm in women; Lv 3, 85-90 cm in men and 80-85 cm in women; Lv 4, 90-95 cm in men and 85-90 cm in women; Lv 5, 95-100 cm in men and 90-95 cm in women; Lv6, $\geq 100 \mathrm{~cm}$ in men and $\geq 95 \mathrm{~cm}$ in women.

with obesity. ${ }^{15}$ In the 2017 Obesity Fact Sheet, higher incidences of hypertension and type 2 diabetes mellitus were observed as BMI levels increased. ${ }^{3}$ In addition to these findings, present findings suggest that incidences of both diseases are associated with increasing WC levels as well as increasing BMI levels in Koreans. Previous studies have reported that $\mathrm{WC}$ was a strong predictor for hypertension incidence independent of BMI. ${ }^{16-18}$ Consistent with previous evidence, our study showed that increased WC was associated with increased incidence of hypertension. A number of mechanisms are associated with this increased incidence of hypertension. Visceral adipose tissue produces proinflammatory cytokines, angiotensino- gen, cortisol, leptin, and reactive oxygen species; activates the sympathetic nervous system and the renin-angiotensin system; and promotes insulin resistance. ${ }^{19-21} \mathrm{WC}$ is considered to be an important predictor for the development of type 2 diabetes mellitus. ${ }^{22} \mathrm{~A}$ significant proportion of Asian adults have normal BMI at the time of type 2 diabetes mellitus diagnosis, and WC is strongly correlated with type 2 diabetes mellitus in European and Asian adults. ${ }^{15,23}$ Our findings support the positive association between WC and incidence of type 2 diabetes mellitus in East Asians. Visceral fat excess is associated with decreased insulin sensitivity and results in poor glycemic control that may be further linked to the development of diabetes. ${ }^{24}$ 
Although the association of BMI with CVDs and mortality has been intensively investigated, the correlations between CVD incidence and indices of abdominal obesity appear to be closer than those of BMI. ${ }^{25}$ Several studies have revealed that abdominal obesity measures are superior to $\mathrm{BMI}$ in predicting the risk of CVDs. ${ }^{26}$ Moreover, excessive fat mass in the body, rather than excessive body weight, is the leading cause of the increased risk of CVDs among obese individuals. ${ }^{27}$ Our study provides additional evidence on the positive association between WC and incidence of myocardial infarction and ischemic stroke. Abdominal obesity may contribute to CVDs via various pathways related to oxidative stress, inflammation, steroid hormones, free fatty acids, and altered production and function of adipocyte-derived hormones. ${ }^{28}$ Recent imaging studies of cardiac metabolism conducted in large cohort studies have shown that hyperplastic visceral fat exceeds its storage capacity and is oversaturated, resulting in a spillover of lipids contributing to metabolic and cardiac abnormalities. ${ }^{29}$ Excessive visceral fat is related with insulin resistance and all proatherogenic factors; subsequent endothelial vasomotor dysfunction, hypercoagulable state, and dyslipidemia are provoked, ultimately leading to CVDs. ${ }^{30}$

Supported by convincing scientific evidence, the World Cancer Research Fund listed that seven cancers (oesophageal adenocarcinoma and cancers of the pancreas, colorectum, postmenopausal breast, endometrium, kidney, and liver) have causal relationships with obesity. The International Agency for Research on Cancer reported that sufficient evidence supports the association between excess body fat and cancer at 13 sites (oesophagus [adenocarcino$\mathrm{ma}$ ], gastric cardia, colorectum, liver, gallbladder, pancreas, postmenopausal breast, endometrium, ovary, kidney, meninges [meningioma], thyroid, and plasma B cells [multiple myeloma]). A recent meta-analysis with strong evidence consistently reported that 11 cancers are associated with adiposity. ${ }^{31}$ Because of our use of WC as the marker for adiposity, our findings not only support but also provide additional evidence to these previous findings.

There are some limitations to our study. First, discrepancies in disease diagnosis may have occurred because we used operational definitions for the definition of each disease. Second, we assessed incidence rates of diseases and all-cause mortality rate standardizing by age and sex; however, we could not account for the various confounding factors for each disease. However, this study was rep- resentative of the entire Korean population and evaluated mortality rate and the incidence rates of substantial outcomes including type 2 diabetes mellitus, hypertension, CVDs, and cancers according to WC categories.

In conclusion, based on information from the 2018 Obesity Fact Sheet, higher WC levels are associated with increased mortality and incidence of chronic diseases as well as higher medical expenses. Developing policies to reduce abdominal obesity for the prevention of abdominal obesity-related comorbidities and decrease in the medical expenses is a public health priority.

\section{CONFLICTS OF INTEREST}

The authors declare no conflict of interest.

\section{ACKNOWLEDGMENTS}

This work was partially supported by the Korean Society for the Study of Obesity.

We would like to thank the Korean National Health Insurance Corporation and all the participants of the study and health checkup.

\section{AUTHOR CONTRIBUTIONS}

Study concept and design: GEN, YHK, KH, WYL, and SJY; acquisition of data: GEN, YHK, KH, WYL, and SJY; analysis and interpretation of data: all authors; drafting of the manuscript: GEN, YHK, WYL, and SJY; statistical analysis: KH, JHJ, and YGP; obtained funding: Taskforce Team of the Obesity Fact Sheet of the Korean Society for the Study of Obesity; administrative, technical, or material support: all authors; and study supervision: WYL and SJY.

\section{REFERENCES}

1. Swinburn BA, Sacks G, Hall KD, McPherson K, Finegood DT, Moodie ML, et al. The global obesity pandemic: shaped by global drivers and local environments. Lancet 2011;378: 804-14. 
2. Nam GE, Park HS. Perspective on diagnostic criteria for obesity and abdominal obesity in Korean adults. J Obes Metab Syndr 2018;27:134-42.

3. Seo MH, Kim YH, Han K, Jung JH, Park YG, Lee SS, et al. Prevalence of obesity and incidence of obesity-related comorbidities in Koreans based on National Health Insurance Service Health Checkup Data 2006-2015. J Obes Metab Syndr 2018; 27:46-52.

4. Wang YC, McPherson K, Marsh T, Gortmaker SL, Brown M. Health and economic burden of the projected obesity trends in the USA and the UK. Lancet 2011;378:815-25.

5. Kuk JL, Lee S, Heymsfield SB, Ross R. Waist circumference and abdominal adipose tissue distribution: influence of age and sex. Am J Clin Nutr 2005;81:1330-4.

6. Flegal KM, Graubard BI, Williamson DF, Gail MH. Cause-specific excess deaths associated with underweight, overweight, and obesity. JAMA 2007;298:2028-37.

7. Franzosi MG. Should we continue to use BMI as a cardiovascular risk factor? Lancet 2006;368:624-5.

8. Blüher S, Molz E, Wiegand S, Otto KP, Sergeyev E, Tuschy S, et al. Body mass index, waist circumference, and waist-to-height ratio as predictors of cardiometabolic risk in childhood obesity depending on pubertal development. J Clin Endocrinol Metab 2013;98:3384-93.

9. Song SO, Jung CH, Song YD, Park CY, Kwon HS, Cha BS, et al. Background and data configuration process of a nationwide population-based study using the Korean national health insurance system. Diabetes Metab J 2014;38:395-403.

10. Kim YH, Han K, Son JW, Lee SS, Oh SW, Kwon HS, et al. Data analytic process of a nationwide population-based study on obesity using the national health information database presented by the National Health Insurance Service 2006-2015. J Obes Metab Syndr 2017;26:23-7.

11. WHO Expert Consultation. Appropriate body-mass index for Asian populations and its implications for policy and intervention strategies. Lancet 2004;363:157-63.

12. Lee SY, Park HS, Kim DJ, Han JH, Kim SM, Cho GJ, et al. Appropriate waist circumference cutoff points for central obesity in Korean adults. Diabetes Res Clin Pract 2007;75:72-80.

13. Seo MH, Lee WY, Kim SS, Kang JH, Kang JH, Kim KK, et al.
2018 Korean Society for the Study of Obesity Guideline for the Management of Obesity in Korea. J Obes Metab Syndr 2019;28:40-5.

14.Lee YH, Han K, Ko SH, Ko KS, Lee KU; Taskforce Team of Diabetes Fact Sheet of the Korean Diabetes Association. Data analytic process of a nationwide population-based study using national health information database established by National Health Insurance Service. Diabetes Metab J 2016;40:79-82.

15. Decoda Study Group, Nyamdorj R, Qiao Q Lam TH, Tuomilehto J, Ho SY, et al. BMI compared with central obesity indicators in relation to diabetes and hypertension in Asians. Obesity (Silver Spring) 2008;16:1622-35.

16. Ostchega Y, Hughes JP, Terry A, Fakhouri TH, Miller I. Abdominal obesity, body mass index, and hypertension in US adults: NHANES 2007-2010. Am J Hypertens 2012;25:1271-8.

17. Bombelli M, Facchetti R, Sega R, Carugo S, Fodri D, Brambilla $\mathrm{G}$, et al. Impact of body mass index and waist circumference on the long-term risk of diabetes mellitus, hypertension, and cardiac organ damage. Hypertension 2011;58:1029-35.

18. Levine DA, Calhoun DA, Prineas RJ, Cushman M, Howard VJ, Howard G. Moderate waist circumference and hypertension prevalence: the REGARDS Study. Am J Hypertens 2011; 24:482-8.

19. Mathieu P, Poirier P, Pibarot P, Lemieux I, Després JP. Visceral obesity: the link among inflammation, hypertension, and cardiovascular disease. Hypertension 2009;53:577-84.

20. Furukawa S, Fujita T, Shimabukuro M, Iwaki M, Yamada Y, Nakajima Y, et al. Increased oxidative stress in obesity and its impact on metabolic syndrome. J Clin Invest 2004;114:1752-61.

21.DiBona GF. The sympathetic nervous system and hypertension: recent developments. Hypertension 2004;43:147-50.

22. Lee J, Cho YK, Kang YM, Kim HS, Jung CH, Kim HK, et al. The impact of NAFLD and waist circumference changes on diabetes development in prediabetes subjects. Sci Rep 2019;9: 17258.

23. Tseng $\mathrm{CH}$. Body mass index and waist circumference as determinants of coronary artery disease in Taiwanese adults with type 2 diabetes mellitus. Int J Obes (Lond) 2006;30:816-21.

24. Gastaldelli A, Miyazaki Y, Pettiti M, Matsuda M, Mahankali S, Santini E, et al. Metabolic effects of visceral fat accumulation 
in type 2 diabetes. J Clin Endocrinol Metab 2002;87:5098-103. 25. Pischon T, Boeing H, Hoffmann K, Bergmann M, Schulze $\mathrm{MB}$, Overvad $\mathrm{K}$, et al. General and abdominal adiposity and risk of death in Europe. N Engl J Med 2008;359:2105-20.

26. Cho JH, Rhee EJ, Park SE, Kwon H, Jung JH, Han KD, et al. The risk of myocardial infarction and ischemic stroke according to waist circumference in 21,749,261 Korean adults: a nationwide population-based study. Diabetes Metab J 2019;43: 206-21.

27. Emerging Risk Factors Collaboration, Wormser D, Kaptoge S, Di Angelantonio E, Wood AM, Pennells L, et al. Separate and combined associations of body-mass index and abdominal adiposity with cardiovascular disease: collaborative analysis of 58 prospective studies. Lancet 2011;377:1085-95.
28. Neeland IJ, Ayers CR, Rohatgi AK, Turer AT, Berry JD, Das $\mathrm{SR}$, et al. Associations of visceral and abdominal subcutaneous adipose tissue with markers of cardiac and metabolic risk in obese adults. Obesity (Silver Spring) 2013;21:E439-47.

29. Wilson PW, D’Agostino RB, Sullivan L, Parise H, Kannel WB. Overweight and obesity as determinants of cardiovascular risk: the Framingham experience. Arch Intern Med 2002;162: 1867-72.

30. Garcia-Garcia HM, Jang IK, Serruys PW, Kovacic JC, Narula J, Fayad ZA. Imaging plaques to predict and better manage patients with acute coronary events. Circ Res 2014;114:1904-17.

31. Kyrgiou M, Kalliala I, Markozannes G, Gunter MJ, Paraskevaidis E, Gabra H, et al. Adiposity and cancer at major anatomical sites: umbrella review of the literature. BMJ 2017;356:j477. 